\title{
Evaluation of Cathodic Arc Deposited Thick CrAlSiN Coatings by Erosion Test
}

\author{
Wei-Yu Ho, Yen-Sho Chang, Bo-Yi Chou, Chien-Liang Lin* \\ Department of Materials and Energy Engineering, MingDao University, Changhua, Taiwan \\ Email: ${ }^{*}$ cllin@mdu.edu.tw
}

Received December 2014

\begin{abstract}
CrAlSiN with thickness up to $16 \mu \mathrm{m}$ was deposited on tungsten carbide via multi-deposition process by cathode arc deposition technique. Scratch and water-sand jet impingement erosion tests were carried out to evaluate the adhesion by determining the worn surface of the coatings. Results showed that the failure mode of the adhesion can be concluded that the weak bond of each CrAlSiN layer as compared to the strong bond between the coating and substrate. The average surface roughness of the coatings before the erosion test was about the same level. After the erosion test of 30 minutes, the eroded CrAlSiN coatings exhibited improved average surface roughness as compared to the original CrAlSiN coatings. Further increasing the erosion up to 60 minutes, the wear and minor peeling of the CrAlSiN coating between each layer was observed. A further research to improve the bond strength between each layer was needed.
\end{abstract}

\section{Keywords}

\section{Cathodic Arc Evaporation, CrAlSiN Coating, Erosion}

\section{Introduction}

Coating deposition techniques effectively improve the durability of the materials in the aggressive environments. Hard coatings are of great success in a number of industrial applications due to their excellent wear and corrosion resistance. In general, coatings with micrometer thick are the basic requirement by physical vapor deposition (PVD) techniques. Over the last decades, coating deposition techniques offer possibilities to tailor coatings with advanced requirement of high thickness in specific industrial application [1]-[7]. With respect to the thick coatings by PVD, the knowledge about the feasible techniques and properties of hard coatings is limited. The reported total thicknesses of the PVD coatings are generally less than $3 \mu \mathrm{m}$, which is probably due to the limited deposition rate and the accumulated high residual stresses as the total coating thickness increased. Recently, CrAlSiN coatings have been intensively studied by cathodic arc deposition (CAD) and sputtering technologies [8]-[14]. CrAlSiN coatings possessed superior hardness, good thermal and chemical stability. However, there is a lack on the further treatment of the thick coatings to modify their properties. Thus, in the present study, CrAlSiN coating were deposited on tungsten carbide by CAD. This study aims to explore thicker CrAlSiN coatings

${ }^{*}$ Corresponding author.

How to cite this paper: Ho, W.-Y., Chang, Y.-S., Chou, B.-Y. and Lin, C.-L. (2015) Evaluation of Cathodic Arc Deposited Thick CrAlSiN Coatings by Erosion Test. Journal of Materials Science and Chemical Engineering, 3, 66-71.

http://dx.doi.org/10.4236/msce.2015.31010 
deposited via multi-depositing cycle process to impact the coating properties. The expected advantages of this process are multilayer structure to improve the toughness and recoating application to recycle the tools. Scratch test and erosion wear tests were carried out on coatings to evaluate the bonding condition of the CrAlSiN coating between each deposition cycle.

\section{Experimental Procedure}

CrAlSiN coatings were deposited on the polished tungsten carbide (WC-10\%Co) substrates by a CAD system. The coating structure comprised the first deposited $\mathrm{CrN}$ of 10 minutes as the adhesion layer, and then CrAlSiN of 60 minutes as the top layer. In order to obtain the CrAlSiN coatings with different thickness, multi-deposition of up to four cycles were separately conducted under the same deposition parameters. The scratch test and water-sand jet impingement erosion test was carried out to evaluate the bond strength of coatings, respectively. Scratch tests were conducted using spherical diamond indenter with cone angle of $120^{\circ}$ and tip radii $\mathrm{R}$ of 200 $\mu \mathrm{m}$. During each test, the normal load was increased from zero to $50 \mathrm{~N}$ until the end of scratch. Scratching speed was set at $5 \mathrm{~mm} / \mathrm{min}$. The bonding conditions of the coatings were determined by the SEM observation of the chipping in the scratch tracks. Erosion tests were performed by using a silica slurry medium at $90^{\circ}$ impingement angle for 30 and 60 minutes, respectively. The erosion tests were conducted with a normal speed of $83.2 \mathrm{~m} / \mathrm{s}$. The slurry consisted of 1 liter water and $7 \mathrm{wt} \%$ silica powders (hardness $1175 \mathrm{~kg} / \mathrm{mm}^{2}$ ) which was shown as Figure 1. The distance between sample and nozzle was $50 \mathrm{~mm}$. After erosion testing, surface roughness and surface morphologies of the eroded specimens was measured using a profile meter and SEM observation, respectively.

\section{Results and Discussion}

Figure 2 shows the thickness of the CrAlSiN coatings deposited with multi-cycle depositions as obtained by cross-section observation of the fracture structures. With the same deposition parameters, the thickness linearly increases from $4 \mu \mathrm{m}$ of 1 cycle to $16 \mu \mathrm{m}$ of 4 cycles. The adhesion of the coatings determined by scratch test is shown as Figure 3 which shows the scratch track and failure mode of the CrAlSiN coating deposited for 4 cycles. It shows the coating with the chipping failure happened at the interface of layers. The observation of the failure mode can be concluded that the weak bond between the CrAlSiN layer as compared to the strong bond between the coating and substrate. From the previous study, the evaluation of the Lc values was obtained by the change of friction forces and chipping failure with an increase from the $26 \mathrm{~N}$ (one cycle) to $35 \mathrm{~N}$ (four cycles) [15]. The gradual increase of Lc as the coating thickness increased was related to an increase of the load capacity of the thicker coatings [6]. During the scratch tests, the elastic field caused by the indenter was a long-range

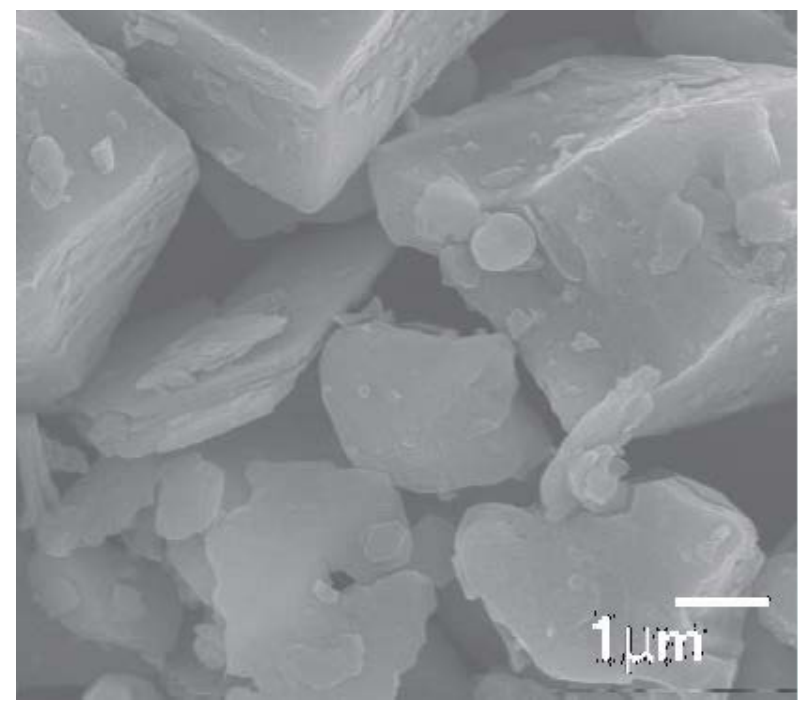

Figure 1. The silica powders $\left(\mathrm{SiO}_{2}\right)$ used for the water-sand jet impingement erosion test. 


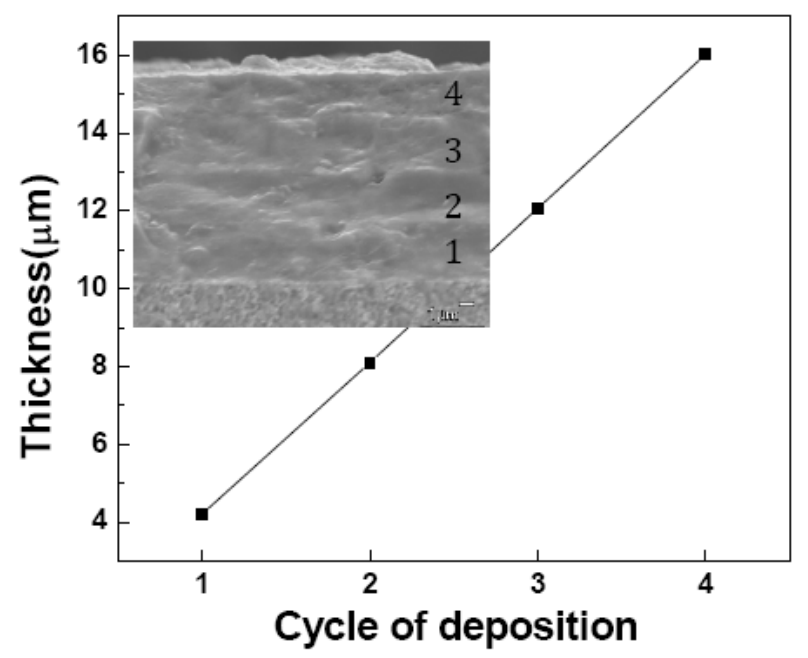

Figure 2. Thickness of the CrAlSiN coatings deposited under different deposition cycles. Cross-section observation of the fracture structures was embedded.

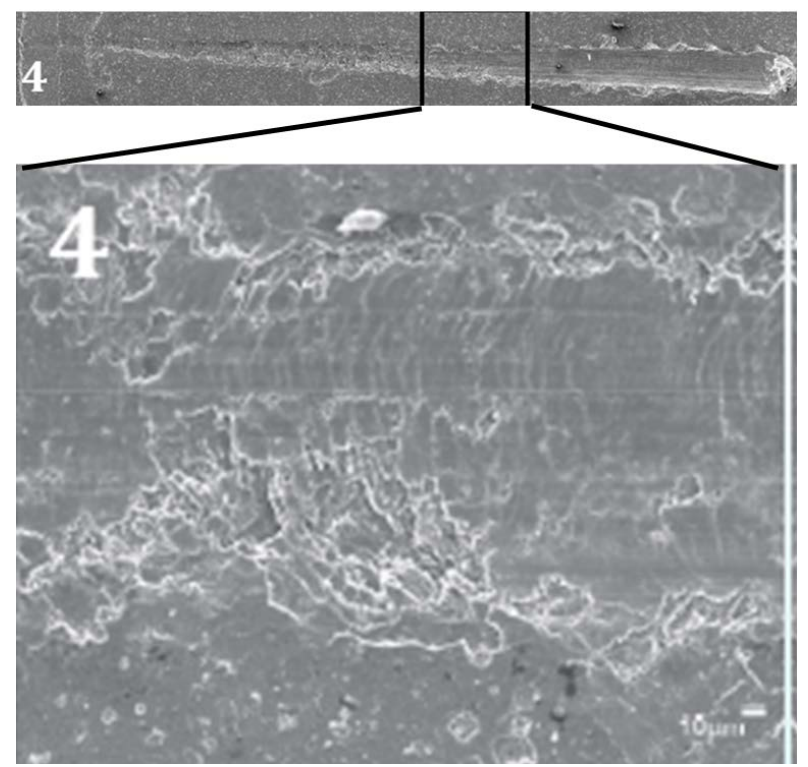

Figure 3. The scratch track of the CrAlSiN coating deposited for 4 cycles. Magnified image of the marked area was shown as below.

field that extended into the substrate. Increasing thickness of the CrAlSiN coatings tended to lower shear strength at the coating-substrate interface as compared to thin coatings, therefore the thick coatings showed higher Lc values.

Figure 4 shows the surface roughness (Ra) of the coated specimens after erosion tests performed for 30 and 60 minutes, respectively. The average surface roughness of the as-deposited coatings before the erosion test was about the same level. After the erosion test of 30 minutes, the similar decrease trend of surface roughness showed that the eroded CrAlSiN coatings exhibited improved average surface roughness than that of the original CrAlSiN coatings. This interesting result possibly accounts for polishing effect for the silica powders on the coating. The reason was mainly from the hardness of the silica powders slurry is much less than that of the CrAlSiN coating. However, the hardness of the silica powders is much higher than that of the droplets which are mainly metallic target material inevitable for CAD process. Therefore, it is expected that droplets and higher 
asperities were removed from the CrAlSiN coatings during the erosion tests. After increasing the erosion of 60 minutes, the surface roughness is increased as compared to that after erosion of 30 minutes. However, the average surface roughness is still lower than that of the original samples. As compared to the 30 minutes erosion, the CrAlSiN coating with multi-cycle depositions shows a rapid increase of average surface roughness after the erosion of 60 minutes, especially for the coating deposited for 4 cycles. The surface morphologies of the CrAlSiN coating deposited for 4-cycles were shown in Figure 5, which shows the surface morphology eroded for different

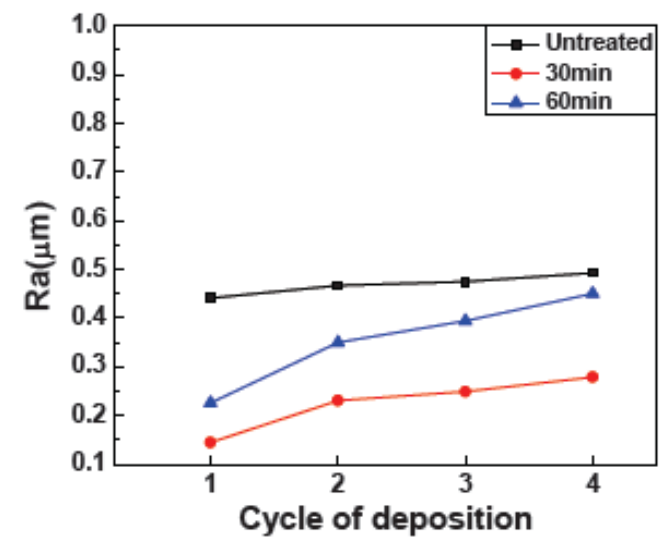

Figure 4. The surface roughness (Ra) of the coated specimens after erosion tests.

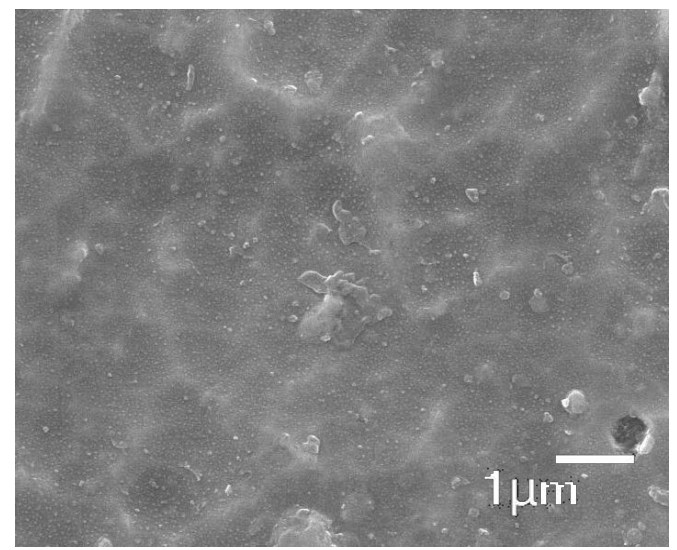

(a)

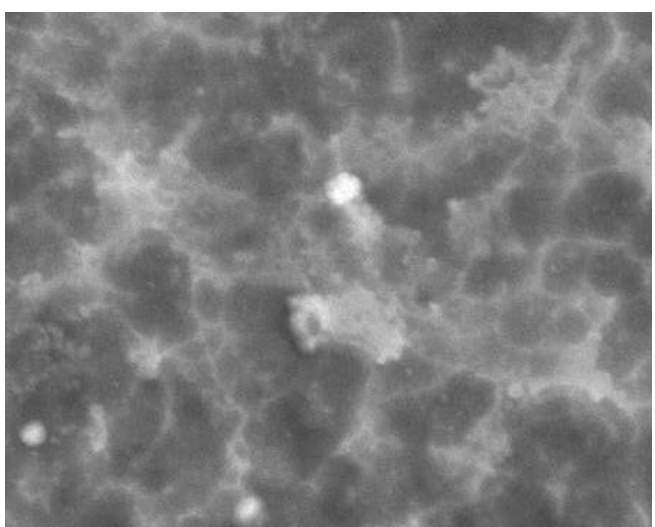

(b)

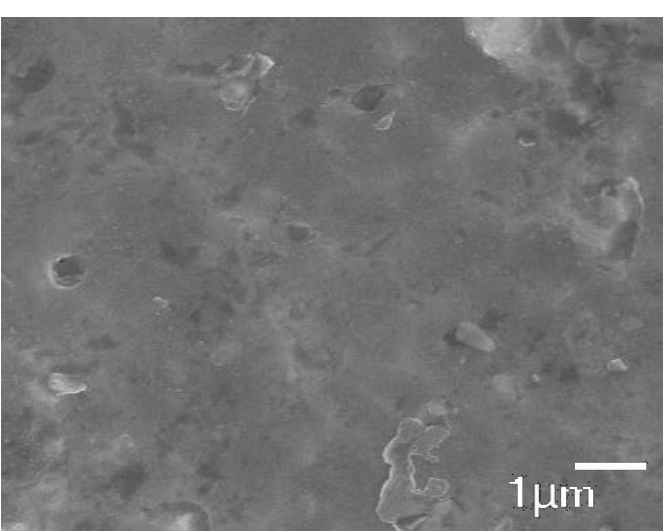

(c)

Figure 5. Surface morphology of the four-cycle deposited CrAlSiN coating after erosion test for different periods. (a) Asdeposited; (b) Tested for 30 minutes; (c) Tested for 60 minutes. 
periods. Compared to the as-deposited coating (Figure 5(a)), after the erosion test for 30 minutes, the structure of the coating is damaged mainly from the grain boundary (Figure 5(b)). However, from Figure 5(c), the structure of the coating became blur appearance which is related to the uniform erosion and increased surface roughness. Analysis of the erosion mechanism demonstrated that the coatings exhibited a typical brittle and cycle fatigue fracture [16]. Under direct impact erosion conditions, the continuity in impact period led to brittle fracture of the multi-layered CrAlSiN coating from layer to layer. Therefore, increase in impact period leads to the upper coating more easily removed by formation of fatigue cracks, which was confirmed by surface examination with SEM. On the other hand, some peeling started from each layer instead from the substrate was observed. The result is also confirmed by SEM/EDS analysis and the scratch test. In the present study, thick CrAlSiN coatings obtained by multi-cycle deposition exhibits the overall improvement in the adhesion to the substrate, however, it still needs a further research to improve the bond strength between each layer.

\section{Conclusion}

CrAlSiN coatings deposited by multi-cycle depositions can be up to $16 \mu$ m by CAD process. By scratch test, the failure mode of the adhesion can be concluded that the weak bond of each CrAlSiN layer as compared to the strong bond between the coating and substrate. The surface roughness of the as-deposited coatings was not related to the deposition cycles. After the erosion test of 30 minutes, the eroded CrAlSiN coatings exhibited improved average surface roughness than that of the original CrAlSiN coatings. Further increasing the erosion of 60 minutes, the impact of the slurry leading to brittle failure and peeling of the CrAlSiN coating between each layer was observed. A further research to improve the bond strength between each layer was needed.

\section{Acknowledgements}

Funding for this work was provided by the Ministry of Science and Technology (MOST), Taiwan, under contract No. NSC 102-2221-E-451-002.

\section{References}

[1] Van Stappen, M., De Bruyn, K., Quaeyhaegens, C., Stals, L. and Poulek, V. (1995) Deposition and Properties of Thick Corrosion and Wear-Resistant $\mathrm{Ti}_{2} \mathrm{~N}$ Coatings. Surface and Coatings Technology, 74-75, 143-146. http://dx.doi.org/10.1016/0257-8972(95)08225-5

[2] Lang, F.Q. and Yu, Z.M. (2001) The Corrosion Resistance and Wear Resistance of Thick TiN Coatings Deposited by Arc Ion Plating. Surface and Coatings Technology, 145, 80-87. http://dx.doi.org/10.1016/S0257-8972(01)01284-1

[3] Zhao, S.-S., Du, H., Zheng, J.-D., Yang, Y., Wang, W., Gong, J. and Sun, C. (2008) Deposition of Thick TiAlN Coatings on $2024 \mathrm{Al} / \mathrm{SiC}_{p}$ Substrate by Arc Ion Plating. Surface \& Coatings Technology, 202, 5170-5174. http://dx.doi.org/10.1016/j.surfcoat.2008.05.041

[4] Lin, J.L., Sproul, W.D., Moore, J.J., Lee, S. and Myers, S. (2011) High Rate Deposition of Thick CrN and $\mathrm{Cr}_{2} \mathrm{~N} \mathrm{Coat}^{-}$ ings Using Modulated Pulse Power (MPP) Magnetron Sputtering. Surface \& Coatings Technology, 205, 3226-3234. http://dx.doi.org/10.1016/j.surfcoat.2010.11.039

[5] Gorokhovsky, V.I. (2010) Characterization of Thick Ceramic and Cermet Coatings Deposited by an Industrial-Scale LAFAD Process. Surface \& Coatings Technology, 204, 1216-1221. http://dx.doi.org/10.1016/j.surfcoat.2009.10.027

[6] Lin, J.L., Sproul, W.D. and Moore, J.J. (2012) Tribological Behavior of Thick CrN Coatings Deposited by Modulated Pulsed Power Magnetron Sputtering. Surface \& Coatings Technology, 206, 2474-2483.

http://dx.doi.org/10.1016/j.surfcoat.2011.10.053

[7] Shi, P.Z., Wang, J., Tian, C.X., Li, Z.G., Zhang, G.D., Fu, D.J. and Yang, B. (2013) Structure, Mechanical and Tribological Properties of CrN Thick Coatings Deposited by Circular Combined Tubular Arc Ion Plating. Surface \& Coatings Technology, 228, S534-S537. http://dx.doi.org/10.1016/j.surfcoat.2012.04.041

[8] Kim, S.K., Le, V.V., Vinh, P.V. and Lee, J.W. (2008) Effect of Cathode Arc Current and Bias Voltage on the Mechanical Properties of CrAlSiN Thin Films. Surface and Coatings Technology, 202, 5400-5404. http://dx.doi.org/10.1016/j.surfcoat.2008.06.019

[9] Tien, S.-K., Lin, C.-H., Tsai, Y.-Z. and Duh, J.-G. (2007) Effect of Nitrogen Flow on the Properties of Quaternary CrAlSiN Coatings at Elevated Temperatures. Surface and Coatings Technology, 202, 735-739. http://dx.doi.org/10.1016/j.surfcoat.2007.06.042

[10] Chang, Y.-Y., Chang, C.-P., Wang, D.-Y., Yang, S.-M. and Wu, W. (2008) High Temperature Oxidation Resistance of 
CrAlSiN Coatings Synthesized by a Cathodic Arc Deposition Process. Journal of Alloys and Compounds, 461, 336341. http://dx.doi.org/10.1016/j.jallcom.2007.06.084

[11] Polcar, T. and Cavaleiro, A. (2011) High-Temperature Tribological Properties of CrAlN, CrAlSiN and AlCrSiN Coatings. Surface and Coatings Technology, 206, 1244-1251. http://dx.doi.org/10.1016/j.surfcoat.2011.08.037

[12] Chen, H.-W., Chan, Y.-C., Lee, J.-W. and Duh, J.-G. (2010) Oxidation Behavior of Si-Doped Nanocomposite CrAlSiN Coatings. Surface and Coatings Technology, 205, 1189-1194. http://dx.doi.org/10.1016/j.surfcoat.2010.08.156

[13] Ding, X.-Z., Zeng, X.T. and Liu, Y.C. (2011) Structure and Properties of CrAlSiN Nanocomposite Coatings Deposited by Lateral Rotating Cathod Arc. Thin Solid Films, 519, 1894-1900. http://dx.doi.org/10.1016/j.tsf.2010.10.022

[14] Endrino, J.L., Palacín, S., Aguirre, M.H., Gutiérrez, A. and Schäfers, F. (2007) Determination of the Local Environment of Silicon and the Microstructure of Quaternary $\mathrm{CrAl}(\mathrm{Si}) \mathrm{N}$ Films. Acta Materialia, 55, 2129-2135. http://dx.doi.org/10.1016/j.actamat.2006.11.014

[15] Chang, Y.-S., Ho, W.-Y., Tsou, P.-Y. and Lin, C.-L. (2014) Advanced Materials Research, 900, 517-521.

[16] López, D., Sánchez, C. and Toro, A. (2005) Corrosion-Erosion Behavior of TiN-Coated Stainless Steels in Aqueous Slurries. Wear, 258, 684-692. http://dx.doi.org/10.1016/j.wear.2004.09.015 